\title{
KORELASI BERAT BADAN DAN KEKUATAN OTOT TUNGKAI TERHADAP KELINCAHAN TUBUH SISWA PENCAK SILAT
}

\author{
Gusti Ayu Agung Nina Utari Dewi ${ }^{1}$ I Gusti Putu Ngurah Adi Santika² \\ 1,2Prodi Pendidikan Jasmani Kesehatan dan Rekreasi FPOK IKIP PGRI Bali \\ Email: agungnina01@gmail.com¹, ngurahadisantika@gmail.com² \\ DOI: https://doi.org/10.36526/kejaora.v5i1.838
}

\begin{abstract}
ABSTRAK
Pencak silat merupakan cabang olahraga yang menitik beratkan pada teknik penguncian, berjalan atau mengayun, menjatuhkan, pukulan, tendangan dan menghindari serangan dari sudut dan arah yang tidak terduga-duga. Segala teknik yang dilakukan akan melibatkan berat badan dan kekuatan otot tungkai, berdasarkan hal tersebut peneliti melakukan penelitian ini dengan tujuan sejauh mana hubungan antara berat badan kekuatan otot tungkai terhadap kelincahan tubuh. Selain itu pencak silat merupakan olahraga yang memiliki teknik menghindar dan merubah arah. tujuan dari penelitian ini adalah untuk mengetahui adanya korelasi antara berat badan dan kekuatan otot tungkai terhadap kelincahan tubuh siswa pencak silat. Metode penelitian yang dipergunakan dalam penelitian ini adalah Metode Korelasional. Berdasarkan nilai r hitung (Pearson Correlations) diketahui nilai r hitung untuk hubungan berat badan $\left(\mathrm{X}_{1}\right)$ dengan kelincahan tubuh $(\mathrm{Y})$ adalah sebesar 0,732 $>\mathrm{r}$ tabel yaitu $0,732>0,339$, maka terdapat hubungan atau korelasi antara variabel berat badan (X1) dengan variabel kelincahan tubuh $(Y)$. Selanjutnya diketahui nilai $r$ hitung untuk hubungan kekuatan otot tungkai $\left(\mathrm{X}_{2}\right)$ dengan pkelincahan tubuh $(\mathrm{Y})$ adalah sebesar $0,923>r$ tabel yaitu $0,923>0,339$, maka terdapat hubungan atau korelasi antara variabel kekuatan otot tungkai $\left(\mathrm{X}_{2}\right)$ dengan kelincahan tubuh $(Y)$. Berdasarkan pembahasan di atas dapat disimpulkan bahwa terdapat hubungan antara berat badan $\left(\mathrm{X}_{1}\right)$ dan kekuatan otot tungkai $\left(\mathrm{X}_{2}\right)$ terhadap kelincahan tubuh $(\mathrm{Y})$.
\end{abstract}

Kata Kunci: Berat Badan, Kekuatan Otot Tungkai, Kelincahan

\section{PENDAHULUAN}

Olahraga adalah segala aktifitas atau kegiatan yang dapat mendorong, mengembangkan serta membina potensi jasmaniah dan rohaniah seseorang (Santika, 2015). Pengertian olahraga ini dimaksudkan tidak hanya melatih tubuh kita secara jasmani tetapi rohani juga ikut dilatih didalamnya. Dengan seimbangnya kondisi fisik dan rohani maka seseorang akan menuju ke kesehatan jiwa raga. Apabila kita secara teratur melaksanakan olahraga, kita dapat menjaga kesehatan tubuh agar tetap dalam keadaan sehat walafiat.

Kualitas kesehatan seseorang penting untuk dijaga demi kelangsungan hidup manusia (Santika, 2015). Ini tiada lain adalah untuk mengkonsistensikan kondisi tubuh kita dalam menghadapi rutinitas keseharian. Dalam keseharian kita tidak hanya membutuhkan makan dan minum serta istirahat, tetapi lebih dari itu kita juga harus aktif untuk melakukan pergerakan tubuh salah satunya dengan berolahraga yang baik dan benar. Baik dan benar dalam hal ini adalah olahraga sesuai dengan kaidah yang ada. Olahraga yang sesuai dengan kaidah yang adalah olahraga dengan tidak mengabaikan denyut nadi. Batasan kita melakukan olahraga akan diatur oleh denyut nadi, apabila semakin rendah umur seseorang, maka denyut nadi maksimalnya semakin besar otomatis aktivitas olahraganya maksimal. Sedangkan apabila semakin tinggi umur seseorang, maka denyut nadi maksimalnya semakin kecil otomatis aktivitas olahraganya minimal (Adiatmika, IPG dan Santika, IGPNA, 2016).

Pencak silat merupakan cabang olahraga yang menitik beratkan pada teknik penguncian, berjalan atau mengayun, menjatuhkan, pukulan, tendangan dan menghindari serangan dari sudut dan arah yang tidak terduga-duga (Pratama, dkk, 
Jurnal Kejaora: Jurnal Kesehatan Jasmani dan Olah Raga

ISSN: 2541-5042 (Online)

ISSN: 2503-2976 (Print)

Volume 5 Nomor 1, Edisi April 2020

2016). Selain itu pencak silat merupakan olahraga yang memiliki teknik menghindar dan merubah arah (Suryanata, dkk, 2018). Olahraga ini juga memerlukan keterampilan gerakan kaki dan tungkai (Padmawan, dkk, 2020). Dengan banyaknya item dalam cabang olahraga pencak silat mengindikasikan bahwa olahraga pencak silat sangat menekankan pada kecepatan gerak dan kelincahan. Ini tiada lain karena dalam olahraga pencak silat apabila lawan melakukan serangan, maka kita harus dengan cepat dan sigap menghindari serangan tersebut. Sebaliknya apabila kita telah berhasil menghindar dengan baik, maka kita harus dengan cepat dan lincah melakukan serangan balasan dengan tujuan lawan terkena serangan yang kita berikan. Agar atlit pencak silat dapat bergerak secara cepat dan lincah tidak akan terlepas dari yang namanya berat badan serta kekuatan otot tungkai. Ini tiada lain karena dalam proses gerak yang cepat faktor tinggi badan dan kekuatan otot tungkai secara tidak langsung terlibat di dalamnya.

Perkembangan olahraga pencak silat terutama pada siswa SMP PGRI 1 Denpasar pada event porsenijar tingkat kabupaten dan provinsi belum menunjukan prestasi yang memuaskan. Apabila atlit ingin berprestasi maka mereka wajib memiliki kondisi fisik yang baik. Kondisi fisik tersebut meliputi Daya Tahan Kardiovaskular, Ketepatan, Keseimbangan, Kekuatan, Kecepatan, serta Kelincahan. Selain itu kunci dan penekanan pada peregangan ini adalah pada cara gerakannya yang dilakukan secara perlahan, yaitu dilakukan dengan cara yang halus dan tidak menghentak-hentakan. Sedangkan gerakan yang terkontrol artinya gerakan yang dilakukan mencapai luas ruang gerak dari persendian yang dikenai latihan. Menurut Suwirman dan Supriadi (2019) bahwa pencak silat merupakan cabang olahraga yang dipertandingkan berdasarkan berat badan. Kelincahan juga dipengaruhi oleh postur tubuh dalam hal ini berat badan (Dewi, 2015). Selain itu menurut Karyono (2016) kondisi fisik kelincahan (agylity) dipengaruhi oleh kondisi fisik yang lain salah satunya kekuatan otot tungkai. Oleh karena itu berdasarkan uraian di atas komponen berat badan dan

kekuatan otot tungkai berkaitan dengan kelincahan tubuh. Berdasarkan latar belakang di atas maka penulis melakukan penelitian yang berjudul : "Korelasi Berat Badan dan Kekuatan Otot Tungkai Terhadap Kelincahan Tubuh Siswa Pencak Silat".

Adapun rumusan masalah yang diajukan dalam penelitian ini adalah : apakah ada korelasi antara berat badan dan kekuatan otot tungkai terhadap kelincahan tubuh siswa pencak silat? Berdasarkan rumusan masalah yang telah dipaparkan di atas maka tujuan dari penelitian ini adalah : untuk mengetahui adanya korelasi antara berat badan dan kekuatan otot tungkai terhadap kelincahan tubuh siswa pencak silat.

\section{Korelasi}

Korelasi merupakan sebuah instrument penelitian yang digunakan untuk mencari hubungan dan membuktikan hubungan dua variabel berbentuk interval atau rasio dan sumber data dari kedua variabel atau lebih tersebut adalah sama (Sugiyono, 2013). Korelasi adalah salah satu analisis dalam statistik yang dipakai untuk mencari hubungan antara variabel yang bersifat kuantitatif (Santika, IGPNA, Subekti, $M, 2020)$. Korelasi product moment adalah teknik analisis yang digunakan untuk mencari hubungan dan membuktikan hipotesis hubungan antara satu variabel independent dan satu variabel dependent dan sumber data dari dua variabel tersebut adalah sama (Sugiyono, 2013).

\section{Berat Badan}

Berat badan adalah ukuran yang lazim atau sering dipakai untuk menilai keadaan suatu gizi manusia (Anonim, 2011). Berat badan diukur dengan alat ukur berat badan dengan satuan ukur kilogram (Santika, IGPNA dan Subekti, M, 2020). Pengukuran berat badan dilakukan mempergunakan pakaian yang sesuai dengan kaidah pengukuran berat badan. Berat badan sangat penting dalam olahraga pencak silat, berat badan yang ideal akan memungkinkan atlit untuk bergerak secara efesien dan efektif. Terdapat beberapa prosedur dalam pengukuran berat badan menurut (Adiatmika, IPG dan Santika, IGPNA, 2016) diantaranya : 
Jurnal Kejaora: Jurnal Kesehatan Jasmani dan Olah Raga

ISSN: 2541-5042 (Online)

ISSN: 2503-2976 (Print)

Volume 5 Nomor 1, Edisi April 2020

1) orang coba diharapkan mengenakan pakaian yang agak ketat dan ringan sehingga tidak mengganggu pada waktu pengukuran dilakukan, 2) hasil pengukuran dikatakan akurat apabila orang coba hanya menggunakan pakaian dalam, 3) pada saat melakukan pengukuran, orang coba tidak boleh mempergunakan alas kaki, 4) apabila orang coba sudah melakukan pengukuran, catat hasil.

\section{Kekuatan Otot Tungkai}

Kekuatan otot tungkai merupakan salah satu komponen biomotorik yang tidak terpisahkan dari cabang olahraga. Kekuatan otot tungkai apabila kita lihat dari perannya dalam olahraga pencak silat sangat penting. Ini terlihat dari kuda-kuda yang sering dipakai dalam olahraga pencak silat. Sebelum melakukan elakan serta serangan, setiap pesilat akan memposikan diri pada sikap kuda-kuda, di mana sikap kuda-kuda ini membutuhkan kekuatan otot tungkai untuk menopang berat tubuh. Selain untuk menopang berat tubuh, kekuatan otot tungkai juga berperan dalam proses elakan (menghindar) serta melakukan tendangan. Menurut (Adiatmika, IPG dan Santika, IGPNA, 2016) prosedur pengukuran kekuatan otot tungkai diantaranya : 1) melakukan pemanasan (warming-up) sebelum melakukan pengukuran, 2) orang coba berdiri di atas leg dynamometer tanpa alas kaki, 3) ke dua tangan memegang bagian tengah tongkat pegangan leg dynamometer setinggi acetebula, 4) mata rantai diatur hingga posisi punggung tetap tegak lurus tetapi kedua lutut ditekuk membentuk sudut $115^{\circ}$, 5) pastikan sebelum melakukan pengukuran jarum petunjuk/angka pada layar berada pada angka nol, 6) tarik nafas dalam dan dengarkan aba-aba kemudian lakukan gerakan meluruskan kedua tungkai atas dan bawah sekuat-kuatnya dengan gerakan perlahan, letak tongkat pegangan harus tetap berada setinggi acaetebula, 7) pengukuran dianggap tidak berhasil apabila : tongkat pegangan dynamometer bergeser kearah bawah ; posisi punggung tidak tegak ; ke dua tangan ikut serta membantu menarik tongkat ke atas ; melakukan gerakan menghentak.

\section{Kelincahan}

Kelincahan adalah kemampuan seseorang untuk mengubah posisi yang berbeda dalam kecapatan tinggi (Santika, IGPNA dan Subekti, M, 2020). Arah yang dimaksud adalah depan, belakang, kanan, kiri, serta diagonal. Begitu pentingnya kelincahan dalam olahraga pencak silat membuat pesilat harus membekali dirinya dengan komponen bimotorik kelincahan. Apabila kita lihat dalam teknik yang ada dalam pencak silat seperti teknik elakan (menghindar) dalam hal ini menghindari serangan lawan, maka atlit pencak silat wajib untuk secara lincah menghindari serangan yang ada. Setelah melakukan elakan (menghindar) atlit pencak silat diwajibkan untuk melakukan serangan balasan. Terkait dengan serangan balasan ini juga atlit wajib mempergunakan kelincahannya untuk mendekatkan diri kelawannya, sehingga dengan kelincahan yang baik akan dengan mudah atlit mendekatkan diri ke tubuh lawan, sehingga gerakan selanjutnya yaitu atlit dapat memukul, menendang, atau memberikan sapuan terhadap lawannya.

\section{Hipotesis}

Berdasarkan uraian di atas maka peneliti mengajukan hipotesis dalam hal ini hipotesis alternatif yang berbunyi adanya korelasi antara berat badan dan kekuatan otot tungkai terhadap kelincahan tubuh siswa pencak silat.

\section{METODE}

1. Rancangan Penelitian, Populasi dan Sampel

Penelitian ini merupakan penelitian korelasi dikarenakan dalam penelitian ini bertujuan untuk mengetahui adanya hubungan Berat Badan dan Kekuatan Otot Tungkai terhadap Kelincahan Tubuh Siswa Pencak Silat. Penelitian ini mempergunakan 3 variabel yaitu 2 variabel bebas dan 1 variabel terikat. Variabel bebasnya yaitu berat badan dan kekuatan otot tungkai, sedangkan variabel terikatnya yaitu kelincahan tubuh siswa pencak silat. Rancangan penelitian yang dipergunakan adalah rancangan penelitian korelasional. 


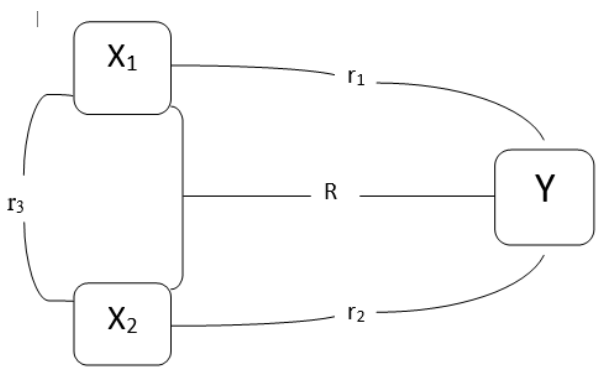

Gambar 1. Rancangan Penelitian Korelasional

Keterangan Gambar :

$\mathrm{X}_{1}$ : Berat badan

$X_{2}$ : Kekuatan otot tungkai

$Y$ : Kelincahan tubuh siswa pencak silat

$r$ : Koefesien korelasi produk momen

$\mathrm{R}$ : Koefesien korelasi ganda

Populasi adalah wilayah generalisasi yang terdiri atas obyek/subyek yang mempunyai kualitas dan karakteristik tertentu yang di terapkan oleh peneliti untuk dipelajari dan kemudian ditarik kesimpulan. Dalam penelitian ini populasinya adalah siswa pencak silat SMP PGRI 1 Denpasar sebanyak 34 orang. Dalam penelitian ini penulis mempergunakan teknik sampling jenuh (Sugiyono, 2013). Sampel jenuh adalah sensus di mana semua anggota populasi dipergunakan sebagai sampel. Adapun kriteria sampel dalam penelitian ini adalah : 1) kriteria inklusi yang meliputi (berstatus sebagai siswa SMP PGRI 1 Denpasar serta memiliki jenis kelamin laki-laki), 2) kriteria ekslusi yang meliputi (drop out yang artinya status sampel akan dibatalkan dikarenakan mengalami cedera pada saat pengukuran). Data yang dianalisis mempergunakan perangkat lunak (SPSS.16) dengan menguji biverate person corelation untuk mengetahui hubungan antara $X_{1}$ (berat badan) dan $X_{2}$ (kekuatan otot tungkai) terhadap $Y$ (kelincahan).

\section{HASIL DAN PEMBAHASAN}

Tabel 1. Tabel Tabulasi Data Pengukuran Berat Badan, Kekuatan Otot Tungkai serta KelincahanSiswa Putra SMP

\begin{tabular}{|c|c|c|c|c|}
\hline \multicolumn{5}{|c|}{ (n) } \\
\hline No. & Nama & $\begin{array}{c}\left(X_{1}\right) \\
\text { Berat Badan } \\
(\mathrm{kg})\end{array}$ & $\begin{array}{c}\left(\mathrm{X}_{2}\right) \\
\text { Kekuatan Otot Tungkai } \\
(\mathrm{kg})\end{array}$ & $\begin{array}{c}(\mathrm{Y}) \\
\begin{array}{c}\text { Kelincahan Tubuh } \\
\text { (detik) }\end{array}\end{array}$ \\
\hline 1 & KDA & 45 & 50 & 14.48 \\
\hline 2 & $\mathrm{TH}$ & 39 & 75 & 13.15 \\
\hline 3 & $\mathrm{DA}$ & 42 & 55 & 14.48 \\
\hline 4 & $\mathrm{KD}$ & 40 & 80 & 12.80 \\
\hline 5 & KW & 39 & 75 & 13.15 \\
\hline 6 & $S$ & 40 & 75 & 13.20 \\
\hline 7 & RS & 45 & 60 & 13.50 \\
\hline 8 & AY & 43 & 70 & 13.45 \\
\hline 9 & $\mathrm{DL}$ & 42 & 65 & 13.33 \\
\hline 10 & MY & 41 & 75 & 13.28 \\
\hline 11 & $\mathrm{~S}$ & 45 & 60 & 13.80 \\
\hline 12 & MA & 43 & 65 & 13.75 \\
\hline 13 & IMYW & 41 & 80 & 12.75 \\
\hline 14 & $\mathrm{~F}$ & 45 & 50 & 14.44 \\
\hline 15 & $\mathrm{~N}$ & 44 & 65 & 13.78 \\
\hline 16 & SB & 43 & 70 & 13.65 \\
\hline 17 & GN & 39 & 75 & 13.05 \\
\hline 18 & $\mathrm{SH}$ & 42 & 65 & 13.27 \\
\hline 19 & RCR & 39 & 70 & 13.18 \\
\hline 20 & $\mathrm{Ml}$ & 45 & 55 & 14.40 \\
\hline 21 & MDIR & 45 & 55 & 14.43 \\
\hline 22 & MYK & 41 & 78 & 13.41 \\
\hline 23 & MYP & 42 & 75 & 13.52 \\
\hline 24 & IKDP & 45 & 50 & 14.45 \\
\hline 25 & KWAP & 39 & 70 & 13.75 \\
\hline 26 & MAS & 45 & 60 & 14.02 \\
\hline 27 & IKNSP & 40 & 80 & 12.81 \\
\hline 28 & IKPY & 39 & 75 & 13.27 \\
\hline 29 & IGADA & 44 & 78 & 13.10 \\
\hline 30 & $\mathrm{GA}$ & 45 & 60 & 14.05 \\
\hline 31 & GASA & 45 & 60 & 14.10 \\
\hline
\end{tabular}




\begin{tabular}{lllll}
\hline 32 & IPYPP & 40 & 75 & 13.15 \\
\hline 33 & KW & 42 & 70 & 13.19 \\
\hline 34 & KABA & 41 & 78 & 13.10 \\
\hline
\end{tabular}

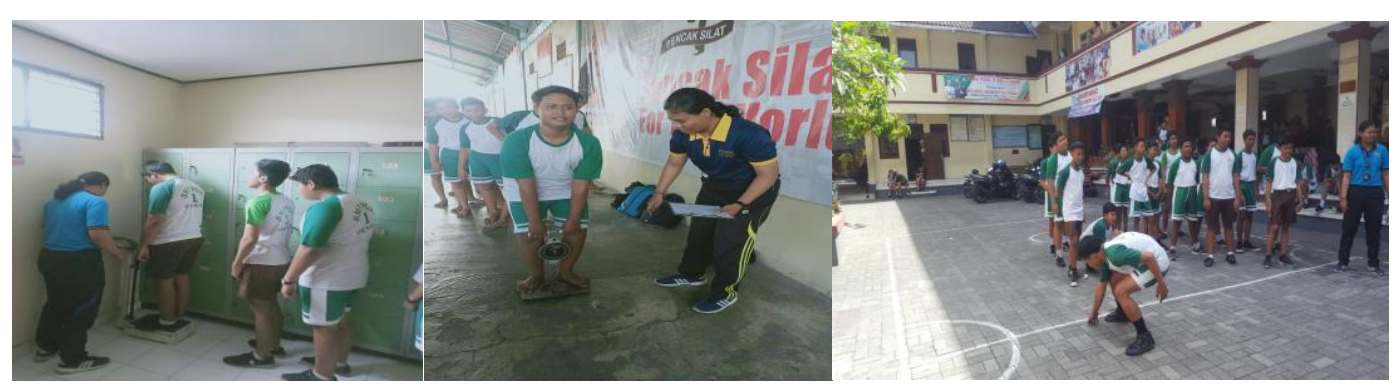

Gambar 2. Dokumentasi Penelitian

Tabel 2. Hasil Analisis Data (Biverate Person Corelation) Antara Berat Badan, Kekuatan Otot TungkaiTerhadap Kelincahan Tubuh

\begin{tabular}{llrrr}
\hline & & Berat Badan Kekuatan Otot Tungkai Kelincahan Tubuh \\
\hline Berat Badan & Pearson Correlation & 1 & $-.770^{* *}$ & $.732^{* *}$ \\
& Sig. (2-tailed) & & .000 & .000 \\
& $\mathbf{N}$ & 34 & 34 & 34 \\
\hline Kekuatan Otot Tungkai & Pearson Correlation & $-.770^{* *}$ & 1 & $-.923^{* *}$ \\
& Sig. (2-tailed) & .000 & & .000 \\
& $\mathbf{N}$ & 34 & 34 & 34 \\
\hline Kelincahan Tubuh & Pearson Correlation & $.732^{* *}$ & $-.923^{* *}$ & 1 \\
& Sig. (2-tailed) & .000 & .000 & \\
& $\mathbf{N}$ & 34 & 34 & 34 \\
\hline
\end{tabular}

Berdasarkan nilai signifikansi Sig.(2tailed) : dari tabel output di atas diketahui nilai Sig. (2-tailed) antara berat badan $\left(X_{1}\right)$ dengan kelincahan tubuh $(Y)$ adalah sebesar $0,00<$ 0,05 , yang berarti terdapat korelasi yang signifikan antara variabel berat badan dengan variabel kelincahan tubuh. Selanjutnya hubungan antara kekuatan otot tungkai $\left(\mathrm{X}_{2}\right)$ dengan kelincahan tubuh $(Y)$ memiliki nilai Sig.(2-tailed) sebesar $0,00<0,05$, yang berarti terdapat korelasi yang signifikan antara variabel kekuatan otot tungkai dengan variabel kelincahan tubuh.

Berdasarkan nilai $r$ hitung (Pearson Correlations) : diketahui nilai $r$ hitung untuk hubungan berat badan $\left(X_{1}\right)$ dengan kelincahan tubuh $(Y)$ adalah sebesar 0,732> $r$ tabel yaitu 0,732 >0,339, maka dapat disimpulkan bahwa ada hubungan atau korelasi antara variabel berat badan (X1) dengan variabel kelincahan tubuh (Y). Selanjutnya diketahui nilai $r$ hitung untuk hubungan kekuatan otot tungkai $\left(\mathrm{X}_{2}\right)$ dengan pkelincahan tubuh $(\mathrm{Y})$ adalah sebesar $0,923>$ $r$ tabel yaitu $0,923>0,339$, maka dapat disimpulkan bahwa ada hubungan atau korelasi antara variabel kekuatan otot tungkai $\left(\mathrm{X}_{2}\right)$ dengan kelincahan tubuh $(\mathrm{Y})$.

\section{KESIMPULAN}

Berdasarkan pembahasan di atas dapat disimpulkan bahwa terdapat hubungan antara berat badan $\left(X_{1}\right)$ dan kekuatan otot tungkai $\left(\mathrm{X}_{2}\right)$ terhadap kelincahan tubuh $(\mathrm{Y})$. Dengan demikian hipotesis yang berbunyi ada hubungan antara berat badan $\left(X_{1}\right)$ dan kekuatan otot tungkai $\left(X_{2}\right)$ terhadap kelincahan tubuh (Y) dapat diterima. Disarankan kepada para peneliti serta para pelatih yang terlibat dalam olahraga pencak silat dapat memperhatikan unsur berat badan khususnya bagaimana agar berat badan atlit berada dalam keadaan efektif serta sesuai dengan kelas yang diikuti serta kekuatan otot tungkai dalam kaitannya dengan kelincahan tubuh atlitnya. Ini tiada lain karena unsur berat badan dan kekuatan otot tungkai berpengaruh terhadap kelincahan tubuh siswa pencak silat. 
Jurnal Kejaora: Jurnal Kesehatan Jasmani dan Olah Raga

ISSN: 2541-5042 (Online)

ISSN: 2503-2976 (Print)

Volume 5 Nomor 1, Edisi April 2020

\section{UCAPAN TERIMAKASIH}

Ucapan terimakasih peneliti ucapkan kepada Kepala Sekolah SMP PGRI 1 Denpasar atas diberikannya ijin penelitian untuk meneliti siswa yang terlibat langsung pada olahraga pencak silat. Peneliti juga ucapkan terimakasih kepada sampel penelitian yang telah meluangkan waktu, tenaga serta keringatnya untuk mensukseskan penelitian ini. Tidak lupa peneliti ucapkan terimakasih kepada guru olahraga SMP PGRI 1 Denpasar atas kerjasamanya telah ikut serta mendampingi kami dalam melakukan penelitian.

\section{DAFTAR PUSTAKA}

Adiatmika, IPG dan Santika, IGPNA. (2016. Bahan Ajar Tes dan Pengukuran Olahraga. Denpasar : Udayana University Press.

Anonim. 2011. Pengertian Berat Badan. Available from

http://www.sarjanaku.com/2011/09/pe ngertian-berat-badan.html, accesed tanggal 17 Maret 2020.

Dewi, Anita Rusyana. 2015. Hubungan Berat Badan dan Tinggi Badan dengan Kelincahan Pemain Futsal Putri Universitas Negeri Yogyakarta. Yogyakarta : Program Studi IImu Keolahragaan Fakultas IImu Keolahragaan Universitas Negeri Yogyakarta 2015.

Karyono, Trihadi. 2016. Pengaruh Metode Latihan dan Power Otot Tungkai Terhadap Kelincahan Bulutangkis. Yogyakarta : Jurnal Olahraga Prestasi Universitas Negeri Yogyakarta 2016.

Pratama, Yudhi Surya; Parwata, Yoga; Santika, Ngurah Adi. 2016. Pelatihan Lari Amplop Meningkatkan Kelincahan Siswa Putra Peserta Ekstra Kurikuler Pencak Silat SMA Dwijendra Denpasar Tahun Pelajaran 2015/2016. Denpasar : Jurnal Pendidikan Kesehatan Rekreasi, Vol. 2, No. 2, Agustus 2016.

Santika, I Gusti Putu Ngurah Adi. 2015. Hubungan Indeks Massa Tubuh (Imt) Dan Umur Terhadap Daya Tahan Umum (Kardiovaskuler) Mahasiswa Putra Semester II Kelas A Fakultas
Pendidikan Olahraga Dan Kesehatan IKIP PGRI Bali Tahun 2014. Denpasar : Jurnal Pendidikan Kesehatan Rekreasi Vol. 1, No. 1, Juni 2015.

Santika, I Gusti Putu Ngurah Adi. 2015. Tingkat Kelincahan Calon Mahasiswa Baru Putra Fakultas Pendidikan Olahraga Dan Kesehatan IKIP PGRI Bali Tahun 2015. Denpasar : Jurnal Pendidikan Kesehatan Rekreasi Vol. 1, No. 2, Desember 2015.

Santika, I Gusti Putu Ngurah Adi; Subekti, Maryoto. 2020. Hubungan Tinggi Badan Dan Berat Badan Terhadap Kelincahan Tubuh Atlit Kabaddi. Denpasar : Jurnal Pendidikan Kesehatan Rekreasi Vol. 6, No. 1, Januari 2020.

Sugiyono. 2013. Metode Penelitian Pendidikan Pendekatan Kuantitatif, Kualitatif dan R\&D. Bandung : ALFABETA.

Suryanata, I.N.; Yasa, IP Merta; Santika, IGP Ngurah Adi. 2018. Pelatihan Double Dot Drill 2 Repetisi 3 Set Meningkatkan Kelincahan Siswa Putra Peserta Ekstra Kurikuler Pencak Silat SMP Negeri 1 Kuta Selatan Tahun Pelajaran 2016/2017. Denpasar : Jurnal Pendidikan Kesehatan Rekreasi Vol. 4, No. 1, Januari 2018.

Suwirman dan Supriadi. 2019. Penurunan Berat Badan Atlet Pencak Silat. Padang : Jurnal Media IImu Keolahragaan Indonesia Universitas Negeri Padang 2019.

Padmawan, I Putu Rega et al. 2020. Pelatihan Ickey Shuffle Dengan Jarak 6 Meter 4 Repetisi 3 Set Terhadap Kelincahan Siswa Putra Kelas X SMA Negeri 2 Mengwi Badung. Denpasar : Jurnal Pendidikan Kesehatan Rekreasi Vol. 6 , No. Januari 2020 